DOI: https://doi.org/10.24297/jssr.v14i0.8191

\title{
The Influence of New Media Technologies on Nambale Sub County Folklore
}

\author{
Jonai Wabwire, Dr. Pamela Mainye \\ Kisii University, Department of communication and Media studies \\ Wabwirejonai05@gmail.com, pamelacmainye@gmail.com
}

\begin{abstract}
New media technologies have had a tremendous impact on Nambale folk media (folklore) productions. By utilizing the technologies, folklorists have the ability to reach out directly to their fans, which creates a closer community between the two sides. With revolutions in both crowd funding, digital releases, and mobile payment technology, folk media fans also have vastly increased opportunities to consume folk media products such as songs, drama, tales in the ways they wish. Unfortunately, new media technologies have also brought about changes in folk music industry that are not as beneficial to either musicians or fans. With social media taking such a key role in how bands market themselves, they now have to worry not only about the music they create, but also how to sell that music to people. It's not good enough anymore to create good art; folk musicians also need to know how to effectively get people to pay attention to it. New media technologies, and how they are used is a complicated issue for everyone, and this is true within folk music industry as well. It has brought huge improvements in some areas, but also unfortunate consequences in others. As with all things related to social media, the best way to look at these changes is to embrace the positive aspects while trying to find ways to overcome, or at least live with, the negative.
\end{abstract}

Keywords: Folk Media; Folklore, Crowd Funding, New Media Technologies, Social Media, Piracy

\subsection{Introduction}

With the advent of the Internet, the future of old media is bleak (Ahlers, 2006; Gillin, 2004; Project for Excellence in Journalism, 2007). Indeed, displacement theory seems to suggest that the demise of the latter is inevitable. The theory predicts either a reduction in consumption of old media as the consumption of new media increases or the old medium will be replaced by the new medium when overlapping functions appear between them (Newell, Pilotta \& Thomas, 2008). Past research found support for time displacement effect such as television displaced by online media for informational function (Kayany \& Yelsma, 2000) and online video services reduced the time spent on old video media and non-media activities (Lee, Lee \& Kim, 2016). The logical appeal of displacement hypotheses, however, is not always supported in the literature.

There is evidence for the survival of folk media including songs, dances narrations, rituals among others. Researchers often find no (absolute) displacement and conclude that folk media complements the Internet in the provision of news, information and social commentary to their audiences (Bromley \& Bowles, 1995; DuttaBergman, 2004; Nguyen \& Western, 2006). The new medium is seen as supplementing rather than displacing (Althaus \& Tewksbury, 2000) and as complimentary to the folk media (Vyas, Singh \& Bhabhra, 2007). Studies also have showed that most online news consumers spend as much time with consuming folk media content online or via new media technologies (Project for Excellent in Journalism, 2005), indicating a "more pattern" of use of the Internet and traditional media (Nguyen \& Western, 2006).

These facts suggest that "replacement" hypotheses have limited explanatory power for the relationship between folk media and new media. This study provides a fuller explanation, by advancing remediation as a theoretical framework for understanding the relationship. The remediation approach to understanding new media is grounded in media research. Researchers have applied remediation concepts in understanding visual presentation of information and news (Cooke, 2005) to plot design changes between media over time and found 
that folk media and the internet have moved towards media visual convergence. The concepts have also been employed in various other media such as games (Jason, 2010), cinema (Baugh, 2005) and film (Scott and White, 2003) to understand how the use of new media is experienced through the interplay between immediacy and hypermediacy in each medium.

\subsection{Methodology}

This study employed ethnographic research design. The study focused on the folk media of the Nambale Sub County society and data was gathered from the community's folk artists, dancers and consumers of the Nambale Sub County folklor. Data collection method included interviews, focus group discussions and participatory observations. Participants were snowballed to saturation levels. The study conducted eight focus group discussions with folk media fans and sixteen interviews with folk media artists (folklorists) from Nambale Sub County.

\subsection{Results and Discussions}

\section{New media technologies}

New media technologies are online means of interactions among people; involving computer-mediated tools and Internet based applications that allow people to create, process, share or exchange information, ideas, pictures and videos. Kaplan and Haenlein (2010) define social media as "a group of Internet-based applications that build on the ideological and technological foundations of web 2.0 and that allow the creation and exchange of user-generated contents." The following are interview and focus group extracts on the new media technologies applied by Nambale Sub County people:

OI 7: Most of us are running facebook pages, whatsup accounts, I have some of my productions on yutube and am planning to start atwitter handle (Oral interview, August $20^{\text {th }} .2018$ ).

OI: My son who is a student at Kibabi University sometimes when around posts my works on facebook, youtube, twitter, and whatsup. He recently surprised me when he provided a long list of social sites where I can make my work visible. He mentioned things like myspace, flickr, linkedlin, orkut and buzz. I was so amazed by such information (Oral interview. August $29^{\text {th }}$. 2018)

OI 10: With my smart phone I am everywhere with my fork productions. I could be here but somebody in Europe is listening to my folk songs. My facebook account is very active and I always make friends with my fans online as this helps in marketing my folk songs (Oral interview, Sept., 28 ${ }^{\text {th }} .2018$ ).

As folk media fun sometime I just get latest productions from my favourite folk sng artists from yutube almost free of charge. With internet everything is possible (focus group, Oct. $6^{\text {th }} .2018$ )

From the data above, it is clear that the new media technologies are the commonly known social media platforms in Nambale Sub County such as Facebook, Instagram, Twitter, YouTube, Linkedln, MySpace, blogs, Flickr, Buzz, MySpace, Orkut and other highly interactive websites. These social media are media for interaction and relationships; largely informal and they are now popular means of communication and quite accessible. They are popular because they can be accessed with ease on a variety of platforms - laptops, PCs, tablet computers, and smart phones (Dominick 2012, p. 94). Social media just as is the case in Nambale Sub County takes on different forms including internet forums, microblogging, podcasts, social networking, bookmarking, wikis, social curation, weblogging. One folklore artist from Bukhayo North Ward had this to say about the types of new media technologies in use in Nambale:

Ol: 12: We are trying to cope up with new media technologies majority of them are social media platforms such as whatsup, facebook, blogs, youtube, twitter, instagram, Linkedln. To use these social media platforms is tricky but we are gambling with them. In instances where we are stuck we engage the young 
generation who are very conversant with some of these apps. The beauty of this technologies is that we are connected to numerous people who listen and wach our folk production (Oral interview, Sept., 30 th. 2018).

Social media is categorized thus because of its interpersonal and user-generated nature. It is about conversations, community, connecting with the audience and building relationships. It not only allows users to hear what people say about them, their preferences and choices, but also enables users to respond and make comments. Social media embodies features like interactivity, adoptability, portability and convergence. These features have led to their phenomenal growth and usage. The total estimated global active Internet audience is now 625 million. Mobile internet usage has now reached nearly a fifth of all active internet users. From www.matthewingram.com it is stated that there are 200,000, 000 active user of Facebook with 100, 000, 000 users logging on at least once every day in 170 countries/territories in 35 different language. It is also estimated that there are an average of 100 friends for every Facebook user (Bratteteig, 2008). Another obvious characteristic of social media is that it lacks strict institutional gate keeping as present in traditional media. Users of social media have freedom to write and post all sorts of materials, which might not be socially responsible, and unethically right to people connected to them on it.

Furthermore, social media outlets are not paid for. This is one reason that accounts for the large number of users on these sites all around the world. Most of these social media sites are free; users just need to be connected to the Internet, register and they open to a use any social media channel for interaction and communication. Here are examples of popular social media forms: Facebook is a popular free social networking website that allows registered users to create personal profiles, add other users as friends, give status updates, send messages, upload photos and video and keep in touch with friends, family and colleagues. It is the world's largest social network, with more than 1.32 billion monthly active users (Bratteteig, 2008). Users create a personal profile, add other users as friends, and exchange messages, including status updates.

Groups of people among the folk artists and brands create pages and Facebook users can "like" brands' and cultural works pages. Twitter is a free social networking and micro blogging platform that allows registered members to stay connected and broadcast short posts (140-character limit) called tweets. Folk artists on Twitter can follow each other and their fans and rebroadcast other users' tweets. Linkedln is a social networking site designed specifically for professionals with similar areas of interest. It enables users to information and participate in conversations. The goal of the site is to allow registered members to establish and document networks of people they know, trust and connect with professionally. This could be folk media artist, professionals in this area and even fans. Pinterest is a social curation website for sharing and categorizing images and photos found according to individual interests and preferences. Clicking on an image on Pinterest will take you to the original source of the image. For example, if you click on a picture of a an artist's folk productions, the user will be taken to a site where he can purchase or access them. Instagram: this is a free photo and video sharing platform that allows users to apply digital filters, frames and special effects to their photos and then share them with followers and on other social networking sits. Flickr: It is similar to Instagram; it is an image and video hosting website with a community of friends. Photos can be shared on Facebook, Twitter, and other social networking sites. YouTube \& Vimeo: They are websites on which users post videos free of charge which can be accessed and viewed by anyone in the world.

\section{Synergy of New Media technologies and the Nambale folk media industry}

The increasing usage and prominence of new media technologies amongst folk media fans and artists cannot be ruled out as shown by the findings of this study. Here in Kenya, where Nambale Sub County falls, the social media is one which has a growing population of users and audience. This study found out that new media technologies have advanced digital storytelling. The following are sampled interview and focus group discussions below:

Ol 9: With new media technologies like internet, facebook, twitter we are able to give narrations that can be recorded and distributed all over the world. Our productions are not only confined within our 
neighbourhood. This is only possible with social media networks and computer applications with global reach (Oral interview, September, $16^{\text {th }} .2018$ )

New media technologies have enabled us to access recorded productions from artists online. You simply have to be their friends on facebook and ones they post their works there you will be able to find out what they have produced. In fact you can download what they posted and listen or watch them from your house. I got the mulongo narrations and the mbe mukhasi song on facebook and other online platforms (folk group, October $11^{\text {th }} .2018$ )

During performances you can record many scenes with your smart phone. Thereafter you can decide to share on the various social platforms for mulitiple access by the various audiences. This is advantageous to both the artists and their fans (focus group, Oct. 2018)

A digital story can mean many things. The term 'digit means a number and originate from the word finger and counting on the finger (Bratteteig, 2008). Digital also means, "being represented in a digital electronic system, a computer." Cisler (1999) refers to the process of digital storytelling as a combination of traditional storytelling techniques, sometimes combined with live performance techniques, and with the use of multi-media to provide sound and video to supplement the spoken word. "In some creations, everything is online, and the listener or computer user, explores in a non-linear fashion the mix of narrative, photographs, video clips, and sound archives. The act of creating this, could be a single Folklore artist working with his or her computer equipment and memories, or it can be collaborative" (p. 23).

Couldry (2008) refers to digital stories as the range of personal stories now being told in potentially public form using digital media resources, online personal narrative formats such as MySpace and Facebook, textual forms such as weblogs (blogs), the various story forms prevalent on more specialist digital storytelling sites or the many sites where images and videos, including material captured on personal mobile devices, can be collected for wider circulation such as YouTube (p. 388).

One example of a digital story from Nambale Sub County which is featured on the CDS and website according to Ol; 9, September (2018) is "Mulongo" a traditional circumcision narration accompanied with folk circumcision song that encourage men to undergo circumcision. Another good example of digital story is the "mbe omukhasi" aluhya wedding song and many others. CDS first came to fruition in the early 1990s when a group of radical theatre performers and media artists led by Dana Atchley, Joe Lambert and Nina Mullen, decided to explore how digital media tools could be used to inform storytelling practices. Joe Lambert explained the roots of CDS in dStoryNews (2000). "We wanted to motivate people to change their behavior, to change policy, to change the distribution of power and resources. As such, Digital Storytelling for us was more of an idea than a product, more effecting social behavior than consumer behavior. Not that the two are inseparable, quite the opposite, but the emphasis, for us, was on a simple notion - The tools of digital technology should be used to democratize the voice of folklorists and folklore performances globally. This, therefore empower more people than the prior set of analogue tools in contemporary communication" (p. 3).

Digital storytelling is consistent with the move toward a more public-oriented communication model which utilizes new technology to displace the formerly hierarchical, bureaucratic, and sender-oriented approach (Servaes, 1999) with a more Freirian and Marxist inspired vision of a participatory and receiver-oriented approach. This resonates perfectly with folklores since most of them are participatory in nature. Freirian because the "oppressed" are treated as fully human subjects with the authority and capacity to tell their own stories, and Marxist because the power of the content itself may contribute to fulfilling, at least in part, that the "human species has a destiny that is more than life as a fulfilment of material needs" (Servaes, p. 84). In this instance, an argument may be made that digital folklore stories, insofar as their content may be used, shared, dispersed and replicated to educate and dispel stereotypes in a community, that it is more valuable than relying solely on traditional oral storytelling whose audience will be limited to one time and space or than the mass media, whose messages often come from a source outside the community, and are disseminated throughout. 
While the way in which each community interprets the digital stories will be relative to each community, this is true too for the ways in which local people from their communities view digital stories on the Internet even when the story itself does not come directly from that geographically-located community. The potential here for sustainable social change is only just beginning to be explored. Drotner (2008) notes, "The increasing range of communication channels available and the complexity of their uses help push social boundaries of knowledge formation. Established institutions such as the education system, the workplace and broadcast media increasingly need to demonstrate their love of socially accepted discourses and legitimate meaning-making practices." (p. 65).

When applied in this context, digital storytelling contributes to a reconceptualization of the notion of "community" which formerly referred predominantly to geography and ethnicity as structuring notions of collective identity or group relations (Wellman, Boase, \& Chen, 2002). Now that the Internet has made cybercommunities possible, digital folk stories serve as part of the mirror and glue that both reflects and informs these communities. Such communities that do not depend on geography to define them, and who have used the CDS model for digital folklore storytelling include survivors of domestic abuse, children who have been through the foster care system, and people living with HIV/AIDs. But the list goes on.

The global Nature of New media technologies such as Social Media has made it possible for folk media fans and artists to access diverse folk contents from all across the world. Uploading contents on African culture values, lifestyle, dressing, arts, music, and food on social media afford the world to see and appreciate the various aspects of African cultures and Nambale in particular. An artist from Nambale township ward had this to say:

Ol 12: Internet technology has enabled us access folk songs, dances, theatre, from all over the world. This enables us to compare our folk with the rest of the world. In return we are able to improve on our productions (Oral interview, 2018)

Participants in focus group discussions confirmed the ease at which the internet and social media has made it for them to access folk media products.

The internet is like a source for everything we need on folk songs, today I can access any production of my favourite local musician online from any part of the world. Once I get it I can tag or post it on my various online platforms for easy access for my friends. Internet has also made me access folk productions from other parts of the world (focus group, Oct. 2018).

Today I only need money to buy bundles to access internet. While there I access all my favourite folk songs, drama, narrations with a lot of ease. It is rare to miss trending folk media personalities on social networks. (focus group, Oct. 2018)

The ease of access to folk media production online makes it possible for crucial cultural information to get into discussions and writings thus making it easy for the perpetuation of the culture. Social media has enhanced more than ever better the opportunity for African countries to make their own socio cultural statements. In the words of Ohiagu (2014), social media and other internet powered technologies have helped African society develop, enrich and preserve its own cultural values and ensure that it is conspicuously represented in the emerging global culture. An example of utilising the social media for global display is Nigerian Events and Asoebi - an Instagram account solely dedicated to the display of Nigerian traditional wedding attires made with Ankara, Asooke and different local fabrics. This page has thousands of followers giving them opportunity to see various styles and appreciate the Nigerian culture and fabric. From these sites, people replicate the styles for their own use; and in turn making for the sustenance of an aspect of the African culture. The use of social media for the display for African styles and dresses has led to the infusion and diffusion of African prints and materials in the designs of foreign clothes designers. Designers now use African materials to make fabulous attires that are displayed on runways and sold around the globe. This definitely helps in sustaining and nurturing the African culture. 
New media technologies have served as archives for cultural materials (folk songs, dances, narratives. As shown in interview and focus group discussions extracts below new media technologies are areal archive for the traditional folk media material:

IO 4: Facebook, whatsup and internet at large are our archive. Immediately you are done with your folk production, you simply need to record yourself and put the work on the internet. Nobody will manage to erase it from there. For comparative purposes you can access colleagues' productions online without necessarily moving to their places of residence physically. You access all you want the moment you click at the item (Oral interview, 2018)

107: For me facebook is like my store of all productions. Immediately am done with my productions recording i post them on facebook and sometimes yutube. Once I do this am sure that nobody can remove them. I know this sometimes makes too much exposure to my works but I like the popularity that comes with it. (Oral interview, 2018)

Whenever I have bundles to access internet I just goggle the name of my favourite folk musician and I get his or her music. Recently I listened to mama mulayi through internet. To me internet is like my music store where I ran whenever I want to listen to a certain traditional musician (focus group, Oct. 2018).

Being a mass medium that is not transient, new media technologies especially those that form social media can be a repository or archive for The Nambale and African cultural materials thus enabling the sustenance of the culture. Contents on social media are available 24 hours a day; 7 days a week and users have the opportunity of viewing previous content on a site any time. This will mean that social media sites, pages or accounts that are dedicated to African culture displaying - videos, poems, literature, drama, music, images - can be stored and accessed anytime, even in many years to come.

New media have created virtual cultural and ethnic communities that may be beneficial to folk media industry.

OI 3:"We have "tsingalabe" whatsup group. In this forum we discuss matters affecting our production team and the entire "tsingalabe" issues in the region. We recruit members basing of their love for our art. The recorded material could be accessed globally."

OI 5: "We have afacebook page where we display our latest productions to make it easy for our fans to access us. We like it when more people like it online."

As fans of a particular folk artist we form groups which bind us togerther. In other words a certain form of community is formed out of such relationship where we share a particular values and other a spsects of life (focus group Oct. 2018).

Social media builds close interactions among folk media users. It facilitates greater connectedness among users of the same ethnic group; reinforces existing ethnic links and ties. Poster (2010) in Bainum puts it this way "internet use also has the effect of linking together web users with the same ethnicity, into a tightly knit online community." Folk media artists and fans that use social media can create pages displaying African folk media culture. This would offer consumers of African folks in other parts of the world and Africans raised outside the continent a window to fully appreciate African folk productions and its culture/values/heritage. Today there are now pages displayed in African languages showcasing African cultural heritage among them folk media forms. For example, Google luhya folk songs, the bully fighting events etcetera, you will easily find them online.

There are specific groups and handles on Facebook and Twitter that communicate with their members and followers in Nambale Sub County dialects and languages. Agood example of this according to Ol: 7 Oct. (2018) are the Obulala singers, kisoko traditional dancers, Apeo band whatsup groups and facebook pages. This helps to strengthen the language and keep it alive; and overall, helping to sustain the African folk culture alongside Western culture. In online dialogue, individuals can consciously project African folk culture. Users can sometimes 
make posts and comments on Facebook wall and other social media in their local languages. Use African idioms, proverbs, tales and myths that are peculiar to their ethnic group. These build virtual African communities at the same time expressing African folk culture. The social media thus serve as a channel to display and introduce users to different ethnicity, folk media products as well as sustain these ethnic and cultural values and strengthen the ties between users of the same ethnicity.

The Multi-media nature of new media technologies has improved the sharing of folk media productions.

Ol 6: Social media is multimedia; you can post pictures, audio, video and even textual matter of folk media such as songs (Oral interview, Oct. 2018)

Ol 9: can reach my fans easily through online platforms unlike in the ancient days when it was very difficult to reach them. They can access you in various forms since there are options of posting audios, videos and even textual narrations (Oral interview, Oct. 2018).

Social media is multi-media in nature, that is, it allows for written, graphic, pictorial and video elements to be uploaded and shared on it. With this feature of social media, plays, images, skits on different aspects of African culture can be portrayed. Examples are drama on family values, short documentary on preparing an African dish. This extent the traditional productions to a wider hence making the more popular and giving them a bigger reach.

New media technologies have perfected the art of piracy. This study revealed that well-known and older folk musicians who could previously afford to sell their audio cassettes and CDs have lost a substantial portion of their potential earnings due to the widespread sale of pirated recordings. Lesser known musicians do not have the notoriety or resources to obtain recordings in the first place. As a result, the folk music market is currently dominated by local individuals and businesses that use low-cost recording devices to obtain recordings from live performances and sell them at low cost to interested listeners, almost always without permission from the folk musicians.

OI 5:"They record our songs distribute them without our permission, we have nothing to do because we have no money to go to courts"

OI 5: "Sometimes because of piracy you will meet your folk productions presented in functions without your consent. You can't do anything."

When asked about challenges facing folk industry, several folk musicians shared their views on this practice, and on piracy in general. The strongest opinion recorded by this study against piracy was from one of the folk musician in Bukhayo East ward who said:

"The voice should have a price."

This cant be possible with numerous unscrupulous businessmen perfecting the art of piracy in Namabale Sub county. Folk productions are on shelves before their owners launching them officially. The traditional way of distributing music has been affected by the changes that the music industry has gone through. The changes have been caused by the new technologies and the use of the Internet for distributing folk music and other performances as a digital information good (Bockstedt, Kauffman, and Riggins 2006). The different platforms that have given consumers the chance to upload music have presented major challenges to both folk artists and music distributors as they have negatively impacted on music sales.

The move from vinyl records and cassettes to compact discs has made it much easier for illegal reproduction of music due to technological advancements. Borghi (2012, p. 38) notes that, —Digital technologies and the environment of networking have dramatically changed the way by which copyright works are reproduced, distributed and used. This is because digital information goods have become as easily reproducible and 
exchangeable as never before in the history of media. It is not surprising that online distribution of copyright content has attracted much litigation, legislative response and public attention as one of the major issue of the so called digital age.

Record labels and artists have over the years faced massive losses because of the file sharing platforms on the Internet. This record labels' losses in revenue are correlated to the widespread dissemination of copyrighted folk sound recordings via peer to peer networks created for allowing people to unlimited access to folk productions for free. The folk media industry commercial practice has been said to have been slow to catch up with technology. Freedman (2003) is of the view that the blame of the decline in global folk production's sales should not be entirely on illegal downloads from the Internet. There are other factors that include the slowing global economy and the continuing corporate concentration of the music industry leading to the reliance on formulas and reluctance to invest in new artists. Instead of artists criminalizing Internet users, Freedman (2003) urges artists to compete with Internet piracy by looking at other options like legitimate online music distribution and making use of the marketing possibilities provided by the Internet.

New media technologies have led to crowd funding among folk media artists. Through crowd funding artists are able to collect some funds from their willing fans to facilitate their production work.

Ol 4: Wahtsup groups have enabled our fans to raise some funds for the needy artists. There is a time I was supposed to perform in Nambale Town and I had no money. I raised this issue on our whatsup group and within a period of two hours members managed to contribute for me three thousands shillings through mpesa technology which I used to transport my team to the event (Oral interview, Oct. 2018)

Ol7: I have so many performance regalia and instruments which my fans that I have never met bought for me through interactions. They simple contribute after liking your productions. There are those who pledge and honour their pledges without failure (Oral interview, Oct. 2018)

In the last few years, crowd funding has emerged as an alternative source of funding for various types of projects. In the beginning, crowd funding was mainly used to finance artists from different sectors. The establishment of various crowd funding Internet platforms in the music sector (e.g. ArtistShare, SellaBand) made this form of financing interesting for folk musicians. Subsequently, other artistic and creative areas (e.g. film, journalism) have adopted the idea. Funding of companies through the crowd has been discussed intensively since 2010 and explored in practice and theory. Crowd funding is seen as a way to reduce the funding gap in the early stages of new ventures. Funding from venture capitalists and banks for folk artists is usually available only in the later development phases of start-ups. In the early phases of a company's life cycle (pre-seed/seed stage), funding is typically provided by the founder himself, by his friends and family and, if possible, by business angels. If these funds are insufficient, the venture faces a funding gap. This situation has been exacerbated by the financial market crisis.

\subsection{Conclusion}

New media technologies have had a tremendous impact on folk media productions. By utilizing social media, artists have the ability to reach out directly to their fans, which creates a closer community between the two sides. With revolutions in both crowd funding, digital releases, and mobile payment technology, fans also have vastly increased opportunities to consume folk music in the ways they wish. Unfortunately, social media has also brought about changes in folk music industry that are not as beneficial to either musicians or fans. With social media taking such a key role in how bands market themselves, they now have to worry not only about the music they create, but also how to sell that music to people. It's not good enough anymore to create good art; musicians also need to know how to effectively get people to pay attention to it. Social media, and how it is used is a complicated issue for everyone, and this is true within music as well. It has brought huge improvements in some areas, but also unfortunate consequences in others. As with all things related to social media, the best way to look at these changes is to embrace the positive aspects while trying to find ways overcome, or at least live with, the negative. 


\section{References}

1. Ahlers, D. (2006). News consumption and the new electronic media. The Harvard International Journal of Press/politics, 11(1), 29-52.

2. Baugh, L. S. (2005). Cinematic discontents: Addressing a Latina/Latino avant-garde through the browser apparatus. Journal of Film and Video, 57(1-2 Spring/Summer), 57-77.

3. Berger, Helen and Ezzy, Douglas (1998). "The Internet as Virtual Spiritual Community: Teen Witches in the United States and Australia." In Religion Online: Finding ～Faith on the Internet edited by Lorne Dawson and Douglas Cowan, 175-188. New York, NY: Routledge.

4. Bratteteig, T. (2008). Does it matter that it's digital? In K. Lundby (Ed.), Digital storytelling, mediatized stories: Selfrepresentations in new media (pp. 271-284). New York: Peter Lang Publishing, Inc.

5. Cisler, S. (1999). Preserving and stimulating oral tradition using the Internet. Paper presented at the $65^{\text {th }}$ IFLA Council and General Conference, Bangkok, Thailand.

6. Couldry, N. (2008). Mediatization or mediation? Alternative understandings of the emergent space of digital story-telling. New Media Society, 10, 373-391.

7. Dominick, Joseph R. (2012). The Dynamics of Mass Communication Media in the Digital Age (10th ed.) Boston: McGraw Hill.

8. Drotner, K. (2008). Boundaries and bridges: Digital storytelling in education studies and media studies. In K. Lundby (Ed.), Digital storytelling, mediatized stories: Self- representations in new media (pp. 61-85). New York: Peter Lang Publishing, Inc.l

9. Jason, F. (2010). Hypermediating the game interface: The alienation effect in violent videogames and the problem of serious play. Communication Quarterly, 58(1), 96-109.

10. Kaplan, A.M. and Haelein, M (2010) Users of the world, unite. The challenges and opportunities of social media. ScienceDirect. Indiana University press.

11. Lee, S. Y., Lee, S.W., \& Kim, C. (2016). Time displacement effect of online video services on other media in South Korea. Telematics and Informatics, 33(2), 247-255.

12. Newell, J., Pilotta, J. J., \& Thomas, J. C. (2008). Mass media displacement and saturation. The International Journal on Media Management, 10(4), 131-138. Online News Production, Consumption and Immediacy: The Remediation Perspective Bahiyah Omar 265 E-ISSN: 2289-1528 https://doi.org/10.17576/JKMJC-20173303-15

13. Ohiagu, O. P. and Okorie, V. O. (2014). Social Media: Shaping and Transmitting Popular Culture. Covenant Journal Of Communication (CJOC), Vol. 2, No. 1, June 2014. Pp 93 -107.

14. Osho, Sulaiman A. (2010). African Communications System. Abeokuta: ESS-OH Consult Publications.

15. Rabin, A. (2011). Language of instruction in Tanzania schools: Creating class divides and decreasing educational standards. Retrieved August 24, 2013 from www.thinkafricapress.com/tanzania/languageinstruction-tanzania-schools-creating-class-divides-and-decreasing-educational-s

16. Servaes, J. (1999). Communication for development: One world, multiple cultures. Cresskill, NJ: Hampton Press, Inc. 